\title{
Media with Captions and Description to Support Learning among Children with Sensory Disabilities
}

\author{
Juanita Rodriguez, Ed. D ${ }^{1}$, Maria Victoria Diaz, M.S.D ${ }^{2, *}$ \\ ${ }^{1}$ College of Education, University of Puerto Rico, Puerto Rico \\ ${ }^{2}$ College of Arts and Humanities, University of Central Florida, United States
}

Copyright $\mathrm{O} 2017$ by authors, all rights reserved. Authors agree that this article remains permanently open access under the terms of the Creative Commons Attribution License 4.0 International License

\begin{abstract}
The basis of this exploratory research was to study the benefits of using accessible media to enhance students from Hispanic origin with sensory disabilities' reading skills. A mixed method was used to explore the results of the use of captions and description in educational audiovisual content to enhance reading by increasing the vocabulary of students who are sensory disabled (Deaf-D/Hard of Hearing-HH or Visually Impaired-VI/Blind-B) and to motivate them to read by accessing media material. In the intervention teachers of the $\mathrm{HH}$ and of the VI/B explored the previous knowledge their students have on the topic presented, and following Discovery en la Escuela strategy for literacy acquisition using media, combined with accessibility features training, students were asked what they know and what they did not know about the video content. This piece aims to provide appropriate attention to the needs of children with sensory disabilities from Hispanic backgrounds through controlled strategies. Accessible media in Spanish to Hispanic students with hearing or visual challenges, open a new alternative to access information that otherwise is unavailable to them. Based on the results of this research study, it is recommended that teachers of students with sensory disabilities, and regular education teachers who have students with sensory disabilities in their classroom, be trained to use this strategy to provide equal access to the information taught.
\end{abstract}

Keywords Captions, Audio Description, Video Description, UDL, Accessibility, Sensory Disabilities, Deaf, Blind, Literacy

\section{Introduction}

Individuals with sensory disabilities encounter many challenges when accessing audiovisual materials, such as movies, television, Internet videos, and other media. The information in these media is presented in visual and auditory modes, precluding full access by those with visual or hearing disabilities. This reduced access to information limits the opportunities of people who have sensory disabilities to learn from educational media at a rate comparable to peers without visual or hearing disabilities, and puts schoolchildren at a notable disadvantage due to the increased use of audiovisual materials in the classroom.

The National Assessment of Educational Progress (NAEP) recently reported results of the 2015 reading assessments at grade 4 and 8 , showing a large gap between students with and without disabilities. There is a need for interventions and practices to address the gap in reading performance between children with disabilities and their peers in the same grades. To design instructional strategies for effective reading for students with low incidence disabilities, such as deafness, blindness and deaf-blindness, and to enhance outcomes in their reading performance, it is imperative to consider their unique needs (Ferrell, Bruce, \& Luckner, [1]. Individuals with sensory disabilities come from different cultural and linguistic backgrounds, including Hispanics who face additional educational barriers. "Hispanic students are the largest minority group in our nation's schools. But they face serious educational challenges that are hindering their ability to pursue the American dream. We must expand their educational opportunities at every level of the $\mathrm{P}-12$ system to compete with the rest of the world" (Arne Duncan [2]. Educational challenges faced by the Hispanic community remain a major cause of lower academic performance compared to non-Hispanic students, as shown in the National Assessment of Educational Progress results (Hemphill, \& Vanneman, [3]. Consequently, being Hispanic and having a sensory disability poses a greater challenge to students who are pursuing the American dream. Channels of communication of the Hispanic students are impaired due to a disruption of the language input by the hearing loss and using language that is not native to them. The VI/B students are also challenged by the limitation in their oral language 
repertoire needed to understand written materials.

Students with sensory disabilities in Puerto Rico are also facing educational challenges in mastering their first language, Spanish. The Department of Education in Puerto Rico [4] has established a public policy to identify and provide special instruction to students with limited language skills in Spanish (Part A, Title III, ESEA, as amended \& Carta Circular \#25, 2016-2017. This policy also includes students from homes where Spanish is not the first language, who are struggling to master the Spanish skills needed to succeed in achieving the Core Standard adopted by the Puerto Rico Department of Education. The Executive Summary of the Medición y Evaluación para la Transformación Académica (META-PR- Measurement and Evaluation for Academic Transformation) for academic year 2016 presented the results of the test in Spanish for students in grades 5th, 6th, 7th, 8th and 11th. META-PR test is aligned to 2014 Puerto Rico Core Standards. The results showed that only $52 \%$ of students in the 5 th grade performed at the Proficient or Advance (those that performed above the expected achievement) level. Those in the 6th, 7th, 8th, and 11 th grades performed below $50 \%$ at the Proficient or Advanced levels. One can assume that among these are students who are hard of hearing or deaf (HH/D) and those who are visually impaired or blind (VI/B).

Technologies like captioning (CC) and Video Description (DV) are available to provide access to audiovisual materials for individuals with sensory disabilities. CC displays the audio portion of audiovisual material from a television program or other video source as text, allowing a $\mathrm{D} / \mathrm{HH}$ person to access the audio information (Dicapta). DV is the narration of key visual elements from an audiovisual source so that people with visual disabilities can have access to the video information from television programs, movies, videos or any other type of audiovisual materials. Dicapta is a group of professionals who specialize in providing $\mathrm{CC}$ and $\mathrm{DV}$ services that allow access to audiovisual media (www.dicapta.com).

Packer, Vizenor, \& Miele [5] analyzed and summarized the research studies on the benefits of DV. Their analysis showed that DV contributes to gains in knowledge and understanding of visual materials for students who have visual impairments. DV provided greater information retention, increased interest and enjoyment, better social connection, and increased knowledge about the visual world. For those who are HH/D, Newton \& Dell [6] recommended that teachers include the technology of CC in their classroom because it benefits all students and enhances and supports the learning process for deaf students. CC guarantees access to information included in audiovisual materials that are used in schools.
As a complement to the teaching and learning experience, Strassman, MacDonald, \& Wanko [7] suggested the use of digital technologies like television, the Internet, and applications like You Tube to enhance the acquisition of $21 \mathrm{st}$ century skills for all students. These skills include reading and writing. TV programs with $\mathrm{CC}$ and DV provide support to students who are $\mathrm{HH} / \mathrm{D}$ or $\mathrm{VI} / \mathrm{B}$ to increase their attention span, increase participation and provide them motivation to learn, among other benefits. Research has demonstrated that the use of CC improves vocabulary and enhances reading comprehension while providing access to cultural and academic experiences for students (Rowland; Jelinek \& Jackson, [8-9]. Despite the benefits of the use of CC and DV for English-speaking students with sensory disabilities as reported in the literature, there is a lack of information about its effects on students with sensory disabilities whose first language is Spanish. There has, however, been research to show the positive effects of CC for non-disabled children whose first language is Spanish. Ferlazzo [10] for example, reported that ELL students benefit from videos with $\mathrm{CC}$ because it gives them the opportunity to compare their pronunciation in English while watching the written form. By repeating the audios on a regular basis, the ELL students gained confidence in the quality of their English and increased their willingness to participate in the ELL classes. Additionally, DV had been used successfully with students with cognitive disabilities as a tool to increase their vocabulary and foster their creative writing skills. Lectora [11] used digitized short stories with DV to teach reading and writing to her students with cognitive disabilities. The results showed that the students not only were able to answer questions about the stories, but also were also able to write descriptions for other short stories that they created.

\section{The Intervention}

This research was concentrated on the use of closed captions (CC) and video description (DV) in Spanish language audiovisual materials in classrooms in Puerto Rico where students who are $\mathrm{D} / \mathrm{HH}$ or $\mathrm{VI} / \mathrm{B}$ are placed, to respond to the learning challenges faced by students with sensory disabilities. Discovery en la Escuela authorized the use of their audiovisual materials and Dicapta inserted the $\mathrm{CC}$ and DV to the videos. The intervention focused on three aspects: 1) training of teachers in Discovery en la Escuela strategy to support learning (See Figure \#1), 2) training for teachers in data collection for this intervention, and 3 ) appropriate attention to the needs of children with sensory disabilities from Hispanic backgrounds through alternating strategies. 


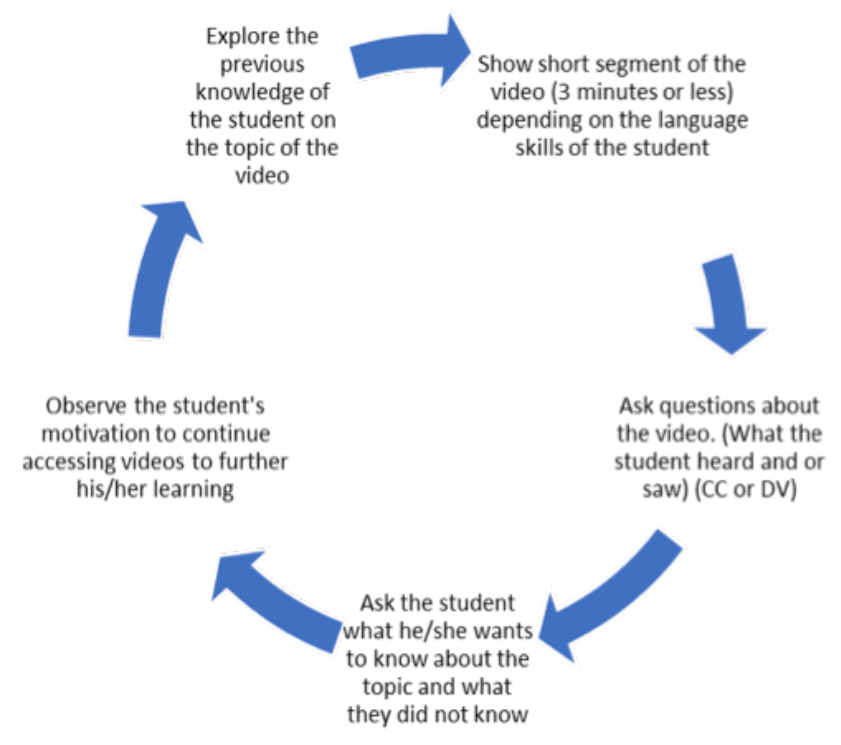

Figure 1. The Strategy Model

The Discovery en la Escuela strategy consists of the following steps: exploring the previous knowledge of the students by asking in advance what they know about the topics of a video they will later be shown; show a small segment (3 minutes) of the video; ask the students questions about what they saw or heard from the video and how it compares with what they knew; ask the student what else they want to know about the topic and what they do not know. The research team included accessibility to this strategy to be used with students with sensory disability. Discovery en la Escuela content will be shown with CC and DV.

When asked about what the students did not know, it gave the students the opportunity to revise what they knew about the topic with the new information acquired and determine what they have learned. For example, the students talked about what they know about elephants; after watching a video one student learned that there were two different kinds of elephants, not only one as he thought. This procedure continues until the end of the video. The teacher advances the video and controls its pace to respond to the students' language skills. While teachers and students talk to each other while listening to (DV) or reading (CC) the video, the students are supposed to confirm their previous knowledge and acquire new information on the topic at a pace that is manageable for them. Opinions from the teacher collected before the intervention will provide teacher's perceptions of what the benefits might be, and the post-intervention opinions will provide teacher views based on their experience acquired during the implementation.

Hence, the intervention is expected to foster the students' motivation to continue watching the videos while reading and acquiring new vocabulary. Inserting $\mathrm{CC}$ and DV in the media make the material accessible not only to students with sensory disabilities but to all learners. As designed, this strategy meets the universal design for learning (UDL
[12] principle as it could be used by all learners, it is flexible to accommodate individual preferences, and it is simple and easy to understand by all learners including those with sensory disabilities (Ralabate; Rose, \& Gravel; Mice, $[13,14,15]$. According to the first principle for an effective UDL, multiple means of representation should be part of the design. Using captions to represent the audio content and descriptions to represent the visual element in educational media content assures that multiple possibilities are presented to the students in the classroom to acquire aural and visual information.

\subsection{Methodology}

The research questions that directed this study were:

- What are the benefits of the systematic strategy of using media with CC and DV for Discovery en la Escuela content in the acquisition of information and the development of vocabulary in Spanish for students with sensory disabilities?

- Whether the exposure to media with CC and DV in Spanish enhances reading skills by increasing the vocabulary of students who are $\mathrm{D} / \mathrm{HH}$ or $\mathrm{VI} / \mathrm{B}$ ?

- Whether the exposure to media with CC and DV in Spanish enhances the motivation to read of Spanish-speaking students who are deaf or blind

\subsection{Content}

Teachers were given access to the accessible audiovisual content provided by Discovery en la Escuela through its website http://discoveryenlaescuela.com/adccvideos or through DVDs with the accessible content (with CC and DV), authorized by the content provider, in some of the schools without Internet access.

Accessibility features (CC and DV) were activated by the teachers at the website. Accessibility features were also available using second screen technology though a technology provided by UC3M. Teachers were instructed in synchronizing the audio of the original video clips with $\mathrm{CC}$ and DV to be utilized as an alternative.

A mixed method was used in this study to explore the benefits of the use of CC and DV in audiovisual material from Discovery en la Escuela to enhance reading by increasing the vocabulary of students who are sensory disabled ( $\mathrm{D} / \mathrm{HH}$ or $\mathrm{VI} / \mathrm{B})$ and to motivate them to read by accessing audiovisual material with CC and VD. A mixed method allows the researchers to gather and analyze both quantitative and qualitative data. According to Zuleta Moreno [16] mixed research is a group of systematic, empirical, and critical research processes in which the data collection and analysis uses qualitative and quantitative methods to achieve a better understanding of the phenomenon studied.

Teachers of students with sensory disabilities were asked their opinions on the possible benefits of the intervention 
before and after the implementation. The opinion of teachers was obtained through a questionnaire with multiple-choice questions and open-ended questions. The sample was a small one; and as such the data collected was not suitable to statistical analysis, other than frequency analysis.

\subsection{Participants}

A group of twelve (12) teachers were invited to participate; six were teachers of students who are $\mathrm{D} / \mathrm{HH}$ and six were teachers of students who are VI/B. Each of six teachers per category was randomly assigned to participate in groups of three. The 12 teachers were selected from the Puerto Rico Department of Education (PRDE) located in different schools throughout the island and from a private school for deaf students who voluntarily agreed to participate in the study. Each teacher participant was assigned a letter (A to $\mathrm{L}$ ) to protect his or her confidentiality.

The criteria to participate in the study were being a teacher of students who was $\mathrm{D} / \mathrm{HH}$ or $\mathrm{VI} / \mathrm{B}$ at the fifth grade or above. Their students should be initiated in reading in Spanish. In other words, Initiated reading level is when the student decodes the words and can explain simple questions like what, how, who. Both the PRDE and the private school authorized the participation of their teachers. Although an effort was made to include an equal number of male and female participants, all participants in this study were female. Based on the research protocol authorized by the University of Puerto Rico-Rio Piedras ${ }^{\wedge}$ (UPRRP) Institutional Review Board (IRB), the 12 teachers received an explanation of the scope of the research, the purpose, the risks and a summary of what was expected from them as voluntary participants. Each signed a consent form agreeing to participate in either the control or the experimental group. After that, teachers were asked to get parental authorization to allow their children to be exposed to the strategy. They also obtained students' agreement to participate in the strategy.

The teacher questionnaire was developed by the principal researcher and project director and validated by two experts in the field. The experts were given the research questions and were asked to determine if the questionnaire, as designed, would provide the information needed to answer the research questions. This instrument was used to obtain the opinions of the participants regarding the benefits of media with CC and VD in reading skills through vocabulary development and motivation to read for their students with sensory disabilities. The first part of the questionnaire asked about demographics of the participants such teachers' highest level of education, years of experience, type of sensory disability of their student(s). In the second part, there were six multiple choice questions about their students' grade level and reading level, their motivation to use $\mathrm{CC}$ or $\mathrm{VD}$, the frequency with which they access media with either $\mathrm{CC}$ or VD and if the content area(s) that they taught were appropriate for using media with CC or VD. There were two open-ended questions: how beneficial was the strategy in fostering reading skills of their students and how it stimulates their motivation to read. The second open question asked the participants recommendations on how to train other teachers of sensory disabilities in the use of the strategy. Table \#1-A summarizes the demographic characteristics of participants.

Most of the participants had more than 10 years of experience teaching students with sensory disabilities. All of them were trained to teach students with sensory disabilities, Deaf Education, or Visually Impaired Education.

Teachers reported that all the participating students had little or no experience with CC or DV.

In Table \#2-A and \#2-B there is a summary of the characteristics of the students and teachers who participated in the intervention.

\subsection{Procedure}

Each participant was interviewed by the researcher in their classroom and asked to sign a consent form before they answered the questionnaire. This procedure was done prior to the implementation of the strategy. Participants were also asked to get consent from the parents of students who would be exposed to the strategy. The students' agreement of the experience was also required. Each teacher prepared a schedule to meet with the researcher every two (2) weeks for follow up on the implementation of the strategy. They were asked to implement the strategy at least once a week for 45 minutes, for eight weeks. With the assistance of the principal researcher, teachers selected the appropriate video to match the content area in which they implement the strategy. Teachers prepared a vocabulary test based on the lesson taught using the selected video with $\mathrm{CC}$ and DV, and were instructed to test the students every two weeks on the new vocabulary and prior to seeing any of the videos. In addition, teachers were instructed to observe changes in students' attitudes toward reading.

Teachers were trained on the strategy prior to the implementation of the intervention in collaboration with the Director of Discovery en la Escuela and the Project Director. Each teacher received a tablet and a videodisk with three videos with CC and VD from Discovery en la Escuela. In training, it was modeled to the teachers how to explore the previous knowledge their students with sensory disabilities have on the topic presented in the video with CC and VD; how to questions the students about what they would like to know about a topic and after viewing a part of the video; then ask students what they did not know about it. For example, after watching the video on the elephants, they may realize that despite the information they had, they acquired new information on the subject, e.g., what the name was of the sound that the elephants made. Participation was encouraged during the training. Teachers were instructed in using second 
screen technology provided by UC3M using the tablet received to synchronize the audio of the original video clips with $\mathrm{CC}$ and DV.

Teachers were asked to register in Discovery en la Escuela to download materials and the Activities Guide that is available online. The researcher then discussed how the teachers will select the content area and how to use it the content area of the Puerto Rico Core Standards provided by the Department of Education in Puerto Rico that they are teaching. The strategy was implemented for eight weeks.

Table 1A. Demographic Data of Participants

\begin{tabular}{|c|c|c|c|c|c|c|}
\hline Teacher & HH/D & HH/D & HH/D & VI/B & VI/B & VI/B \\
\hline Code & A & B & C & D & E \\
\hline $\begin{array}{c}\text { Years of } \\
\begin{array}{c}\text { Experience } \\
\text { teaching }\end{array}\end{array}$ & 2 & 15 & 14 & 20 & 15 \\
\hline \begin{tabular}{c} 
Highest degree \\
\hline $\begin{array}{c}\text { Students grade } \\
\text { level }\end{array}$
\end{tabular} & BA/Deaf Ed & BA+15 cred in Sp.Ed & BA in Sp.Ed. & MA VI ed. & BA+MA in Sp.Ed. & $\begin{array}{c}\text { BA in VI } \\
\text { Ed. }\end{array}$ \\
\hline $\begin{array}{c}\text { Students' } \\
\text { experience with } \\
\text { CC or DV }\end{array}$ & Novice CC & $5^{\text {th }}$ & $\begin{array}{c}6^{\text {th }}(1) \\
7^{\text {th }}(1)\end{array}$ & $12^{\text {th }}(1)$ & $7^{\text {th }}(1)$ & $6^{\text {th }}(2)$ \\
\hline \multicolumn{7}{|c|}{ (All participants were female, teachers of the VI/B did not have experience with DV before the study) } \\
\hline
\end{tabular}

Table 2A. Students who are Hearing Impaired/Deaf who participated in the Intervention

\begin{tabular}{|c|c|c|c|c|}
\hline Teacher & $\begin{array}{c}\text { Age Of The } \\
\text { Student(S) }\end{array}$ & $\begin{array}{c}\text { Grade / Reading } \\
\text { Level** }\end{array}$ & $\begin{array}{c}\text { Motivation Of Student To Use Audiovisual } \\
\text { Material With CC } \\
\text { (Before/After) }\end{array}$ & $\begin{array}{c}\text { How Independently The Student } \\
\text { Accesses Audiovisual Material } \\
\text { With CC } \\
\text { (Before/After) }\end{array}$ \\
\hline A & 11 & $\begin{array}{c}5^{\mathrm{TH}} / \text { Initiated in } \\
\text { reading } \\
6^{\mathrm{TH} /} \text { Initiated in } \\
\text { reading }\end{array}$ & $\begin{array}{c}\text { Poorly motivated/ } \\
\text { Very motivated }\end{array}$ & $\begin{array}{c}\text { Needs a lot of help / } \\
\text { Needs no help }\end{array}$ \\
Needs a lot of help/ \\
N
\end{tabular}

Table 2B. Students who are Visually Impaired/Blind who participated in the Intervention

\begin{tabular}{|c|c|c|c|c|}
\hline Teacher & $\begin{array}{l}\text { Age Of The } \\
\text { Student(S) }\end{array}$ & $\begin{array}{l}\text { Grade / Reading } \\
\text { Level }\end{array}$ & $\begin{array}{l}\text { Motivation Of Student To Use Audiovisual } \\
\text { Material With DV(Before/After) }\end{array}$ & $\begin{array}{c}\text { How Independently The Student Accesses } \\
\text { Audiovisual Material With DV* (Before/After) }\end{array}$ \\
\hline D & 17 & $\begin{array}{l}12^{\text {th }} / \text { average } \\
\text { reading }\end{array}$ & $\begin{array}{c}\text { Motivated/ } \\
\text { Very motivated }\end{array}$ & $\begin{array}{l}\text { Needs some help/ } \\
\text { Needs some help }\end{array}$ \\
\hline $\mathrm{E}$ & 12 & $\begin{array}{l}7^{\text {th }} / 7^{\text {th }} \text { grade } \\
\text { reading level* }\end{array}$ & $\begin{array}{c}\text { Motivated/ } \\
\text { Very motivated }\end{array}$ & $\begin{array}{l}\text { Need no help/ } \\
\text { Need no help }\end{array}$ \\
\hline $\mathrm{F}$ & $\begin{array}{l}11 \\
12\end{array}$ & $\begin{array}{l}6^{\text {th }} / \text { initiated in } \\
\text { reading } \\
6^{\text {th }} / \text { initiated in } \\
\text { reading }\end{array}$ & $\begin{array}{c}\text { Motivated/ } \\
\text { Very motivated } \\
\text { Motivated/ } \\
\text { Very motivated }\end{array}$ & $\begin{array}{l}\text { Needs some help/ Needs some help } \\
\text { Needs a lot of help/ } \\
\text { Needs a lot of help }\end{array}$ \\
\hline
\end{tabular}




\subsection{Results}

Answers to the research questions are presented below. To answer Research Question \#1, the responses of the open questions from the questionnaire are analyzed.

- Question \#1: What are the benefits of the systematic strategy of using media with CC and DV for Discovery en la Escuela content in the acquisition of information and the development of vocabulary in Spanish for students with sensory disabilities?

To answer this question, teachers' responses to the same questionnaire before and after the implementation were compared. One of the open questions in the questionnaire asked teachers' opinions on how the use of CC or DV and the strategy fosters students' reading skills and motivation to read.

One of the teachers commented, "the strategy fosters reading skills because the student acquires new vocabulary". In the vocabulary quizzes, the student demonstrated the acquisition of the new vocabulary that was included in the videos used for the intervention. The teacher added, "the videos with $\mathrm{CC}$ gave the $\mathrm{D} / \mathrm{HH}$ student the opportunity to read while observing the visual images". She reported that her student improved oral reading skills and was motivated to participate in class after the intervention.

Teacher C who worked with three (3) HH students who benefit from their residual hearing, benefited from the audio of the programs. She expressed that "the strategy benefitted her students because it challenged them to use their residual hearing, while giving a visual image of what they were reading". She added: "my students with residual hearing benefitted from DV, as well, because it supports their independence in accessing the information that they are seeking; and as such, it will motivate them to explore the world of information and knowledge". Moreover, she considered that the three modes ( $\mathrm{CC}$, visuals, and audio) presented simultaneously in the video help the students to integrate the information presented and enhance their comprehension of the topic. The teacher added "the strategy stimulated their motivation and curiosity to continue watching the videos. The different ways in which the information is presented in the videos enriches their vocabulary, their knowledge and perception of the world that they were not aware of ". The vocabulary quizzes showed how they were integrating the information with their personal experiences. For example, they compared the way they relate to other peers with the way elephants interact in their community. They also could relate the information to other content area like Mathematics.
Teachers of the VI/B responses to open question \#1 prior to the implementation of the strategy were based on what they thought the strategy might have been. None of these teachers have had experience-using DV in their classroom. Their responses to the questionnaire after the intervention were even more positive and based on their experience with DV. Teacher D expressed that "the strategy fosters my student's reading skills and motivation to read because the audio feedback of the DV and her tactile skills supported her effort to achieve the academic skills at her grade level. All her senses are stimulated with the DV and helped her to concentrate on the tasks that she works on in the classroom. Teacher E commented, "DV provides a total learning experience to her student". Teacher F commented that during the initial session, her student with very low vision was so surprised with the DV because it was the first time that she could understand what was displayed on the screen. After each session, she could describe in her own words what was described in the video. "It fully captured her attention", Teacher E said.

- Question \#2: Whether the exposure to media with CC and DV in Spanish enhances reading skills by increasing the vocabulary of students who are $\mathrm{D} / \mathrm{HH}$ or $\mathrm{VI} / \mathrm{B}$ ?

The teachers of the HH/D answered the pre-questionnaire based on what they thought of $\mathrm{CC}$, as it relates to their personal experience watching $\mathrm{CC}$ in movies, but not as the result of using it as a teaching tool. They also expressed in the pre-questionnaire that the only time that their $\mathrm{HH} / \mathrm{D}$ students were exposed to $\mathrm{CC}$ was when they go to the movies. Movies shown in most theaters in Puerto Rico are in English with CC in Spanish or are dubbed in Spanish for the general audience who do not speak English. Local TV channels in Puerto Rico have their programs in Spanish as well with no $\mathrm{CC}$, unless it is activated. They thought that videos with $\mathrm{CC}$ could help their students to increase their reading level, but had never used the technology as a teaching tool before.

After implementation of the strategy, teachers of students who are HH/D reported that the strategy fosters the acquisition of new vocabulary, which in turn helps enhance the reading skills of the students. Teachers of the $\mathrm{HH} / \mathrm{D}$ in this study had not previously used material with $\mathrm{CC}$ to teach their students. Teacher B, for example, did not have access to the Internet nor videos with $\mathrm{CC}$ prior to her participation in the study. Teacher $\mathrm{C}$ has used materials with $\mathrm{CC}$, but for recreational purposes, not to teach new vocabulary. For teacher $\mathrm{A}$, the $\mathrm{CC}$ was not useful to teach reading to her students. She said that depending on how the CC is used, it may help her students to acquire vocabulary, but that sign language was a better means to understand what she read to them. She used signs and oral Spanish to teach reading to her students. 



Figure 2. Responses of teachers for the HH/D. Increasing reading skills by acquiring new vocabulary

The teachers of VI/B students answered in the pre-intervention questionnaire that DV could help their students enhance their academic achievement. They consider that media with DV could be used as a complementary technique to teach vocabulary. As mentioned before, these teachers had little or no experience using DV in their classrooms. However, after the implementation, the three teachers of the VI/B students agreed that the DV fostered the development of reading skills in their students. Also, Teacher D said the descriptions helped her students with residual hearing improve the use of the hearing input. Hearing the description helped them to understand the visual images on screen. Teacher $F$ also agreed that one of the students with whom she used the strategy had low vision and could see the CC; along with the DV he could confirm what he was watching on the screen. For her other student, whose vision was very low, the DV alone helped her to understand the visual information on the screen.

- Question \#3: Whether the exposure to media with CC and DV in Spanish enhances the motivation to read of Spanish-speaking students who are deaf or blind?

Unanimously, all the teachers considered that the $\mathrm{CC}$ and DV would motivate their students to read and to watch media. Teachers of HH/D students answered before the implementation of the strategy that the $\mathrm{CC}$ could help motivate their students to read. After using the strategy, teachers of the HH/D were more convinced that their students were motivated to read and to watch videos with CC. Their students asked their teachers to provide them with other videos with $\mathrm{CC}$, a reaction that they had never had before, although they watched movies with $\mathrm{CC}$ before.

Before the intervention, teachers of the VI/B also thought DV could motivate their students to read. After the intervention, the three teachers were overwhelmed by how much DV motivated their students to read and to access videos with DV. Teacher F commented that her student with low vision was so surprised when she first heard DV that her face "glowed". She was motivated to talk more about the topic of the video. Teacher D's opinion was that the DV stimulated her student's senses and this motivated her to read and to access other videos with DV. For Teacher E, the technology motivated her student to integrate DV in her learning process.

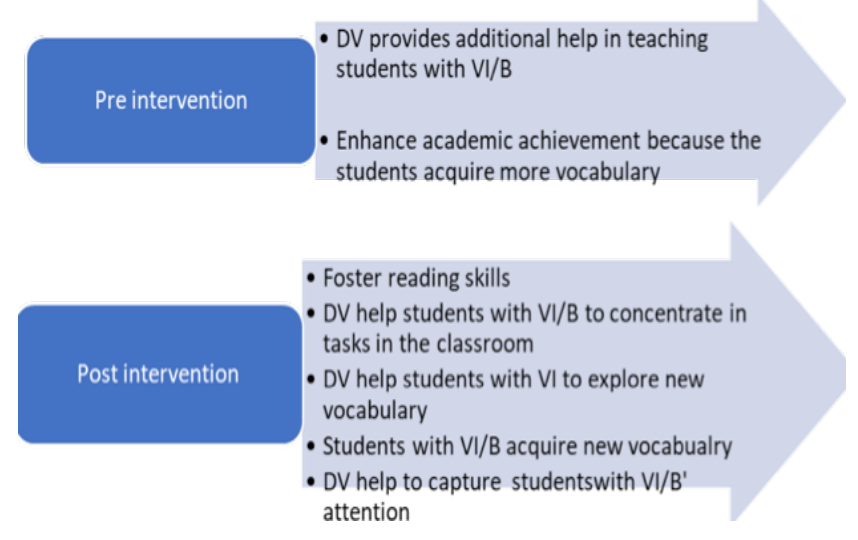

Figure 3. Responses of teachers for the VI/B. Increasing reading skills by acquiring new vocabulary

\section{Discussion}

The purpose of this mixed method exploratory research was to study the benefits of the use of a systematic strategy to use media with CC and DV to enhance students' reading skills by enhancing the vocabulary of students who are HH/D or $\mathrm{VI} / \mathrm{B}$ and to examine whether it motivated them to read. The study aimed to get teachers' opinions before and after training and implementation of the strategy with their students with sensory disabilities. The strategy taught them to use questions to explore the previous knowledge of their students on the topics addressed in the videos from Discovery en la Escuela with CC and DV. An important aspect of the strategy is that the videos were presented in short segments that allowed the teachers to control the pace of the video and adjust it to match their students' linguistic skills. They also used questions to explore what the students learned and what they did not know about the topic. After the implementation for eight weeks, teachers had gained the experience to express their opinion on the benefits of the strategy on their students' reading skills by increasing their vocabulary and motivation to read. Prior to the training and intervention, teachers thought that the intervention could foster the acquisition of new vocabulary and the motivation to read in their students, though none of them had used videos with DV in the past to teach their students. Similarly, teachers for the HH/D also thought that the use of CC was beneficial to their HH/Deaf students, yet they lack the experience of using media with CC to teach content. They used videos with $\mathrm{CC}$ for recreational purposes only.

After implementing the strategy, two major changes occurred in students' vocabulary and motivation to read. The vocabulary of the students regarding the topics of the videos expanded significantly. For example, one of the videos from 
Discovery en la Escuela that was used in the intervention focused on elephants. Before the intervention, students described some characteristics such as elephants' size, trunk, and ears. After watching/listening to the video they could describe other characteristics, such as the habitat where they live, their "community", the two types of elephants, and where they came from. The students could make comparisons based on the elephants' size and shapes, using the appropriate vocabulary.

The teachers of the HH/D expressed that the CC helped their students to understand the videos and were motivated to further explore the topic. They were also motivated to watch other videos with $\mathrm{CC}$ to get information on additional topics. The teachers said that some of the students were more confident to talk in class to share their knowledge with their classmates. The students with HH/D who were beginner readers benefitted from the short periods that the video was shown in because it helped them to read the $\mathrm{CC}$. The picture and the $\mathrm{CC}$ on the screen help the HH/D students understand the information presented.

Jensema, Sharkawy, Danturthi, Burch, \& Hsu [17] found that videos with CC help students who are HH/D from English speaking backgrounds with poor reading skills because it provides information to understand the content of what they are watching. Jelinek \& Jackson [9] also established that $\mathrm{CC}$ assists the HH/D student to understand better what is on a video. For the teachers of the $\mathrm{VI} / \mathrm{B}$, the DV was of great assistance for students with low vision, because the descriptions helped them to understand the images on the screen. (Note that all the students selected by the teachers of the VI/B had low vision.) The students could corroborate what they were watching on the screen with the descriptions. One of the students with low vision could understand the visual information with the aid of the DV. The auditory experience provided by the DV impacted them positively and increased their satisfaction and motivation to continue watching videos with DV.

Previous studies on the use of DV in media in English had shown that all students, including those with visual impairments, who are exposed to this technology, increased their attention and reading and writing skills, as well as their motivation to read (Hoffner, Baker, \& Quinn, [18]. In a paper on the discursive process of DV, Piety [19] reported that Frazier's 1975 thesis demonstrated that audio information enhanced the comprehension of the VI/B person. Fine, Labianca, \& Peli [20] found that DV helped people with low vision and blindness to get details of the visual content of a video. Furthermore, Kirchner \& Schmeidler [21] found that DV was beneficial to VI/B persons because it increased the amount of information understood in a video. They added that participants found the videos interesting as well as informative, which in turn had a positive impact on the users.

Teachers of the VI/B in this study found that the DV in the videos from Discovery en la Escuela impacted their students positively, not only because it was accessible to them, but for the additional information that it provided on the topics. It gave students the opportunity to get a better "picture" from the screen, which enhanced their understanding and motivated them to continue accessing videos with DV. Also, the teachers of the VI/B as well as those of the HH/D students from this study who implemented the strategy agreed that the use of DV or CC helped their students to acquire new vocabulary and motivated them to read.

The results of this exploratory research show that videos with DV and CC used systematically with questions to guide access to this media, foster the acquisition of new vocabulary in students with sensory disabilities from Spanish speaking backgrounds and motivates them to read. The questions about what they knew, what they did not know, and what they have learned that accompanied the watching/listening of the audiovisual material with CC or DV, guided the students to pay attention to details that otherwise would not be considered in understanding the topic of the video. These results are supported by previous studies with students with sensory disabilities from English speaking backgrounds.

The explanation for these results may be that DV and CC provide alternatives that compensate for the child's sensory loss. DV fills the need for the limitation in the visual channel. The auditory channel receives pertinent information to cope with the missing of the visual sense. Likewise, with $\mathrm{CC}$, the visual information compensates for the auditory channel that was missing due to deafness. When teachers presented videos with CC and DV at the linguistic level of the student, whether in the visual or aural mode, it gave students the stimuli to increase attention, enabling them to understand the information presented. Additionally, the questioning regarding previous knowledge alerts them to concentrate on the visual and auditory input to confirm or reject their knowledge. As one of the teachers said, the videos with DV and/or with CC stimulate all the senses that the student has available and so they can use them to their benefit.

Analysis of the results from this mixed method research shed some light on the benefits that accessibility using CC and DV provide to students with sensory disabilities from Hispanic backgrounds.

First, when media with CC and or DV is available in Spanish to Hispanic students with hearing or visual challenges, it opens a new alternative for them to access information that otherwise is unavailable to them. When teachers are trained to use this technology and to control its pace, it guarantees that the students with sensory disabilities grasp the information because it is not above their linguistic capacity.

Second, the use of CC or DV facilitates the acquisition of new vocabulary that enables students with hearing or visual challenges to understand and to connect the information to previous knowledge, which can then be generalized to other content areas and in other contexts.

Third, in the case of students with VI/B, the video descriptions stimulate their hearing comprehension, which serves as a scaffold to oral reading comprehension. In the case of students with $\mathrm{HH} / \mathrm{D}$ the visual access that $\mathrm{CC}$ 
provides is a scaffold to integrate not only new vocabulary but the correct syntax rules of the Spanish language that they need to write.

Fourth, the combined technologies of CC and DV provide double exposure, visually and aural, to students who have residual hearing and residual vision. Input from two channels facilitates the corroboration of information that they receive through vision and hearing, despite the sensory loss. That was the experience of one of the students with low vision. The audio description helped her to understand what she was watching on the screen. When the technology of CC and DV is available to students and it is available at their linguistic level, they are motivated to search for new knowledge.

Considering the universal access to information that the videos with $\mathrm{CC}$ and DV provide to students with sensory disabilities and the questions that guided the experience in the classroom, the benefit of the strategy seems to be the result of the intertwine of the technology of CC and DV and the questioning process studied. Without the access to the content presented in the video, students were not able to respond to questions posed by the teachers.

\section{Implications and Recommendations}

Because of these mixed method research results, it is recommended that teachers of students with sensory disabilities, and regular education teachers who have students with sensory disabilities in their classroom, be trained to use this strategy to provide equal access to the information taught. Since this is a universal design teaching strategy it is accessible and beneficial to all students and nurtures an inclusive environment in any classroom. Teachers are not forced to create additional alternative activities for students with sensory disabilities.

Analysis of the impact of using new technology in the classroom as part of the strategy for inclusion is recommended for further research.

Discovery en la Escuela should include CC and DV in all their TV programs because Hispanic families, even those who do not have sensory disabilities, will benefit from the technology, which may help their children who are struggling with language skills in Spanish.

\section{Acknowledgements}

This research study and the contents of this report were developed under a grant from the U.S. Department of Education \#H327C150009. However, those contents do not necessarily represent the policy of the U.S. Department of Education and you should not assume endorsement by the Federal government. Project Officer: Jo Ann McCann; Project Director: Maria V Diaz. H327C150009 (Closed Caption Latina Corporation) has ED initial protection of human subjects' clearance.

The researchers are thankful to Discovery en la Escuela for letting us use their AV content and for their support in the training of participants. Thanks also to Universidad Carlos III of Madrid for authorization to use their second screen technology to bring access "on demand" for participants of this study.

\section{REFERENCES}

[1] Ferrel, K.A., Finnerty, M. \& Monson, M. (n.d.). American Foundation for the Blind. University of Northern Colorado. Meta-analysis of the descriptive video literature. http://www.dcmp.org/descriptionkey/description_key_meta_a nalysis.pdf

[2] Duncan, A. (2011, June 23). U.S. Secretary of Education, U.S. Challenges Nation to Work Together to Make Hispanic Educational Excellence a Priority.

https://www.ed.gov/news/press-releases/us-

education-secretary-duncan-challenges-nation-work-togethermake-hispanic-educ

[3] Hemphill, F.C. \& Vanneman, A. (2011) Achievement gaps: How Hispanic and white students in public schools perform in mathematics and reading on the National Assessment of Educational Progress

[4] Departamento de Educacion de Puerto Rico (2016-2017) Part A, Title III, ESEA, as amended \& Carta Circular \#25, 2016-2017 Política Pública para la Enseñanza de los aprendices de Español como segundo idioma e inmigrantes en las Escuelas Públicas de Puerto Rico. http://intraedu.de.pr/Cartas\%20Circulares/25-2016-2017.pdf Puerto Rico Department of Education (2016) Executive Summary of the Medicion $y$ Evaluacion para la Transformacion Academica (META-PR) www.de.gobierno.pr/institucion/2692_resultados-meta-pr

[5] Packer, J., Vizenor, K. \& Miele, J. (2015) An overview of video description: History, Benefits and Guidelines. Journal of Visual Impairment \& Blindness, 109 (2), 83-93.

[6] Newton, D.A. \& Dell, A.G. (2009) Film and video technology: Issues of access for hard of hearing and deaf students. Journal of Special Education Technology, 24(4), 47-53.

[7] Strassman, B.K, MacDonald, H., \& Wanko, L. (2010). Using caption media as mentor expository text. The Reading Teacher, 64(3), 197-201. DOI:10.1598/RT.64.3.5.

[8] Rowland, J. (2007). Closed-captioned video and the ESL classroom: A multi-sensory approach. Journal of Adult Education, 36(2) 35-39.

[9] Jelinek, M.S, \& Jackson, D.W. (2001). Television literacy: Comprehension of program content using closed captions for the deaf. Journal of Deaf Studies and Deaf Education, 6(1), 43-53. https://doi.org/10.1093/deafed/6.1.43

[10] Ferlazzo, L. (2017). Student engagement: Key to personalized learning. Educational Leadership, 74(6), 28- 33.

[11] Lectora, E. (2010) Guía para maestros crear cuentos digitalizados con video descripción como material de enseñanza en poblaciones especiales. Academia.edu 
[12] UDL, National Center on Universal Design for Learning. http://www.udlcenter.org/aboutudl

[13] Ralabate, P.K. (2011). Universal design for learning: Meeting the needs of all students. The Asha Leader. http://www.asha.org/Publications/leader/2011/110830/Univer sal-Design-for-Learning--Meeting-the-Needs-of-All-Students

[14] Rose, D.H. \& Gravel, J.W. (2010). Universal design for learning. In P. Peterson, E. Baker, \& B. McGraw (Eds.), International encyclopedia of education (pp.119-124). Oxford:Elsevier.

http://www.udlcenter.org/sites/udlcenter.org/files/Technology andLearning.pdf

[15] Mice, R. (1975). The Center of Universal Design. The principles of universal design, version 2.0. Raleigh, NC: North Carolina State University.

[16] Zuleta Moreno, M. (sf) Investigacion mixta. http://www.slideshare.net/miguelangelzuletamoreno/investiga cion-mixta

[17] Jensema, C.J., Sharkawy, S., Daturic, R.S., Burch, R. \& Hsu, D. (2000). Eye movement patterns of captioned television viewers. American Annal of the Deaf, 145(3), 275-285.

[18] Hoffner, H., Baker, E. \& Quinn, K. (2008). Light, cameras, pencils! Using descriptive video to enhance writing. The Reading Teacher, 61(7), 576-579.

[19] Piety, P.J. (2004). The language system of audio description: An investigation as a discourse process. Journal of Visual Impairment \& Blindness, 98(8), 453-469.

[20] Fine, W. Labianca, A. \& Peli, E. (1996). Evaluating visual information provided by video description. Journal of Visual Impairment \& Blindness, 90(5) 378-385.

[21] Kirchner, C. \& Schmeidler, E. (2001). Adding audio description: Does it make a difference? Journal of Visual Impairment \& Blindness, 95(04)197-212. 